\title{
The Effect of Surface Roughness on Repair Bond Strength of Light-Curing Composite Resin to Polymer Composite Substrate
}

\author{
Timo T. Kallio, Arzu Tezvergil-Mutluay, Lippo V.J. Lassila and Pekka K. Vallittu* \\ Department of Biomaterials Science and Turku Clinical Biomaterials Centre - TCBC, Institute of Dentistry, University \\ of Turku, Turku, Finland
}

\begin{abstract}
Objective: The purpose of this study was to analyze the shear bond strength of a new composite resin to polymer-based composite substrates using various surface roughnesses and two kinds of polymer matrices.

Materials and methods: Particulate filler composite resin with cross-linked polymer matrix and fiber-reinforced composite with semi-interpenetrating polymer matrix were used as bonding substrates after being ground to different roughnesses. Substrates were aged in water for one week before bonding to new resin composites. Twelve specimens in the substrate groups were ground with grinding papers of four grits; 320, 800, 1200 and 2400.

Results: Corresponding values of surface roughness $\left(\mathrm{R}_{\mathrm{a}}\right)$ varied from 0.09 to 0.40 for the particulate filler composite resin and 0.07 to 0.96 for the fiber-reinforced composite resin. Characteristic shear bond strength between the new resin and particulate filler composite resin was highest $(27.8 \mathrm{MPa})$ with the roughest surface (Weibull modulus: 2.085). Fiberreinforced composite showed the highest bond strength (20.8 MPa) with the smoothest surface (Weibull modulus: 4.713).

Conclusions: We concluded that surface roughness did not increase the bonding of new resin to the substrate of IPN based fiber-reinforced composite, whereas the roughness contributed to bonding the new resin to the particulate filler composite resin with a cross-linked polymer matrix.
\end{abstract}

Keyword: Bond strength, composite, repair, adhesion, bonding.

\section{INTRODUCTION}

Repairs of old restorations are common clinical and technical procedures in dentistry. Most often these procedures are related to repairing or replacing an existing composite resin restoration. The declining use of amalgam and other metal restorations and appliances, and the increasing use of composite resin restorations have stressed the importance of the bond strength quality of light-curing composite resin to polymer based composite substrates. By repairing the old restoration intact tooth tissue can often be preserved. The repair process is usually more cost-effective than the fabrication of a new restoration. The use of polymer based devices, e.g. composite fillings of fibre-reinforced composite (FRC), fixed dental prostheses, and crowns have become more popular [1-7]. As the use of polymer based materials increases, the necessity for repairing fractured, discoloured, or worn restorations also increases. In repairs, the durable and reliable adhesive joint between the substrate and the repair composite is crucial for clinical success. Attempts to develop composite repair primers have been made, but the bonding of the new composite to the old composite substrate remains problematic [8].

*Address correspondence to this author at the Institute of Dentistry, University of Turku, Turku, Finland, Tel: +358-2-3338332; Fax: 358-2-3338330; E-mail: Pekka.vallittu@utu.fi
The importance of the age of the polymeric substrate on the repair strength was previously evaluated by Lloyd et al. [9] and Boyer et al. [10]. These studies demonstrated that the bond strength of the composite to the fresh composite was the same as the cohesive strength of the bulk material. Söderholm and Roberts [11] compared the repair bond strength of composite after storing the repaired composite specimens in water for 3 months and 12 months. They discovered that the repaired resin had a tendency to weaken during the storage period. Özcan et al. [12] found that the composite-to-composite bond strength varied in accordance with the specific particulate filler, composite resin, and different surface conditioning methods used. Several methods for repairing polymer based fillings and appliances have been introduced. Usually the bonding procedure includes treating the substrate with adhesive resin, also called intermediate resin, and combining it with a roughened substrate surface by air-particle abrasion or grinding [13-16]. Composite repairs have bond strengths of approximately $20 \%$ to $70 \%$ of the cohesive strength of bulk materials.

In our previous study, the effect of intermediate adhesive resin treatment was evaluated with various substrates [2]. We have also studied the effect of application time of the intermediate resin on bond strength when applied to the composite [17]. Studies have shown that the intermediate resins improved the bond strength of repaired restorative composite [2, 18-20]. Several research groups have found that air-particle abrasion produces satisfactory and repro- 
Table 1. Materials Used in this Study

\begin{tabular}{|c|c|c|c|c|}
\hline Brand & Manufacturer & Lot no. & Code & Chemical composition \\
\hline $\mathrm{Z} 100$ & 3M Dental Products, St. Paul, MN, USA & OHR & $\mathrm{Z} 100$ & Bis-GMA,UDMA, Bis-EMA, TEGDMA \\
\hline everStick & StickTech-GC, Turku, Finland & & eS & $\begin{array}{l}\text { E-glass-fibers impregnated with IPN of di- } \\
\text { methacrylate and PMMA }\end{array}$ \\
\hline $\begin{array}{l}\text { 3M Scotchbond Multipur- } \\
\text { pose Adhesive }\end{array}$ & 3M Dental products, St. Paul, MN, USA & 20011115 & MP & Bis-GMA, HEMA \\
\hline
\end{tabular}

$\begin{array}{ll}\text { PMMA } & =\text { poly(methylmethacrylate) } \\ \text { bisGMA } & \text { bisphenol A-glycidyl dimethacrylate } \\ \text { TEGDMA } & =\text { Triethylene glycol dimethacrylate } \\ \text { UDMA } & =\text { Urethane dimethacrylate } \\ \text { Bis-EMA } & =\text { Bisphenol A polyethylene glycol diether dimethacrylate } \\ \text { HEMA } & =\text { Hydroxyethylemethacrylate } \\ \text { IPN } & =\text { Interpenetrating polymer network }\end{array}$

Table 2. Average Surface Roughness $\left(R_{a}\right)$ of Substrates Being Ground with Grinding Papers of Various Grits

\begin{tabular}{|c|c|c|c|c|}
\hline Substrate & \multicolumn{4}{|c|}{ Surface Roughness ( $\left.\mathbf{R}_{\mathbf{a}}\right)$} \\
\hline & $\mathbf{3 2 0}$ Grit & $\mathbf{8 0 0}$ Grit & $\mathbf{1 2 0 0}$ Grit & $\mathbf{2 4 0 0}$ grit \\
\hline \hline eS tranversal & 0.91 & 0.22 & 0.20 & 0.05 \\
\hline eS longitudinal & 0.85 & 0.29 & 0.20 & 0.03 \\
\hline Z100 & 0.41 & 0.21 & 0.08 & 0.04 \\
\hline
\end{tabular}

ducible bond strength values, although these values are not significantly different from the results obtained with diamond bur grinding [21-23]. Laboratory studies by Crumbler et al. [21], Söderholm et al. [11], and Turner and Meiers [24, $25]$ have also evaluated the strength of repaired composites. These studies showed that the surface irregularity of the composite substrate had a greater influence on bond strength compared to the use of intermediate resin only. Therefore, surface roughness is an important factor in creating high repair strength in cases where repair resin has the necessary physico-chemical properties, which allows for wetting of the rough surface $[23,19]$. The aim of this study was to investigate the influence of surface roughness of a particulate filler composite resin and a fiber-reinforced composite resin substrates on the repair composite.

\section{MATERIALS AND METHODS}

In this study particulate filling composite resin (Z100) was bonded to three different types of substrate. The materials used in this study are listed in Table 1. The substrates for the test specimens were prepared by placing either continuous unidirectional E-glass fiber-reinforced composite (FRC) (everStick), with light-curing semi-interpenetrating polymer network (IPN) polymer matrix, or light-curing particulate filler composite resin (Z100) with cross-linked polymer matrix into the retentive cavity of the supporting acrylic resin block. These were surrounded by a stainless steel cylinder. Both substrates of FRC and particulate filler composite resin were light polymerized with a light-curing hand-unit (Optilux-501, Kerr, CT, USA) for $40 \mathrm{~s}$. The light wavelength was between 380 and $520 \mathrm{~nm}$ with an intensity of $720 \mathrm{~mW} / \mathrm{cm}^{2}$. Both the light wavelength and intensity were verified by an internal radiometer, and the FRC substrate was additionally cured in the oven for $15 \mathrm{~min}$ in Liculite (LicuLite, Dentsply
DeTrey GmbH, Dreieich, Germany). The substrates were stored at $37^{\circ} \mathrm{C}$ in water for one week to age the substrate; i.e. to let the polymerization process and free radical activity complete. The aged substrate surfaces were then wet ground with 320, 800, 1200 and 2400-grit (FEPA) silicon carbide grinding paper (Table 2). 3M Multipurpose adhesive resin was applied as an intermediate resin to the surface of the substrate and left to react for $5 \mathrm{~min}$ in dark conditions and then light cured for $10 \mathrm{sec}$ (Optilux 501). A five minute reaction time was observed to allow for the diffusion of the intermediate resin into the microirregularities and polymer structure of the substrate. Composite resin Z100 was then applied in $2 \mathrm{~mm}$ increments to the substrate surface using a translucent polyethylene mould with a $3.6 \mathrm{~mm}$ diameter. It was then polymerized with a light-curing hand-unit for $40 \mathrm{~s}$.

Twelve specimens $(n=12)$ for each material combination of substrate and Z100 stub were stored in water at $37{ }^{\circ} \mathrm{C}$ for $48 \mathrm{~h}$. Shear bond testing was applied using a universal testing machine (model LRX, Lloyd Instruments, Fareham, England), and the data was recorded using PC-software (Nexygen, Lloyd Instruments Ltd., Fareham, England). The specimens were mounted into a jig (Bencor Multi-T shear assembly, Danville Engineering Inc., San Ramon, CA) and loaded with a circular shearing rod until they fractured with a crosshead speed of $1.0 \mathrm{~mm} / \mathrm{min}$. FRC eS specimens were mounted with their fibers vertically oriented, i.e. along the direction of shear force.

Profilometry (Mitutoyo Surftest 301, Japan) measured the surface roughness (average roughness, $\mathrm{R}_{\mathrm{a}}$ ) of the substrates after grinding. Fiber-reinforced composite substrate was measured in relation to the direction of the fibers; transversally and longitudinally. Three repeated roughness measurements were conducted for each substrate group. 


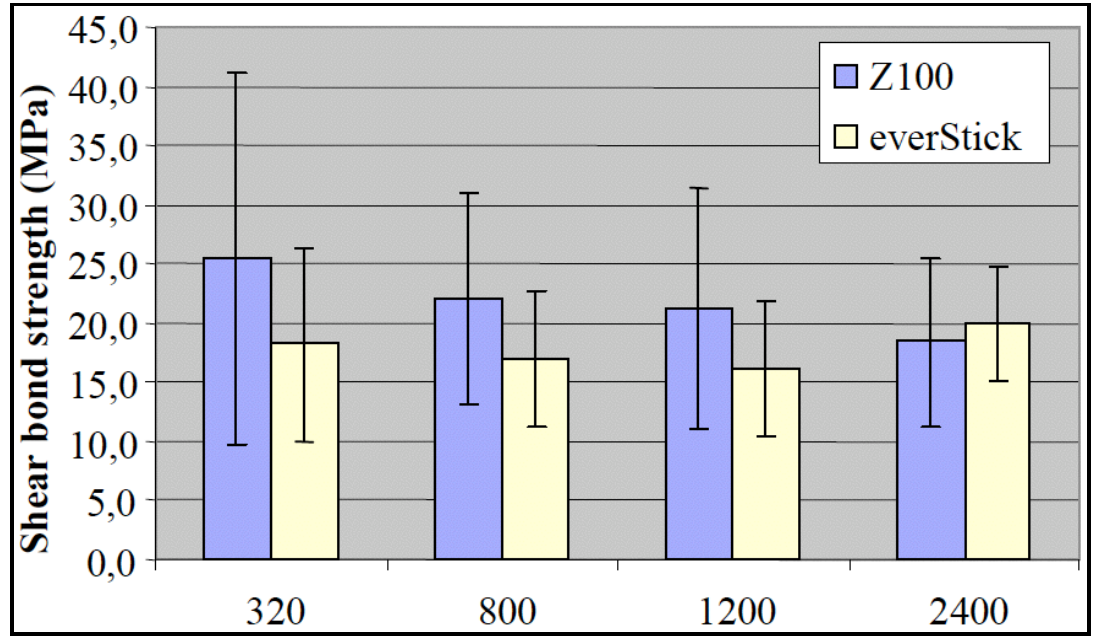

Fig. (1). Mean shear bond strength of particulate filler resin composite to substrate of composite Z100 and FRC eS which have been ground with different grit size grinding papers. Vertical lines represent standard deviations.

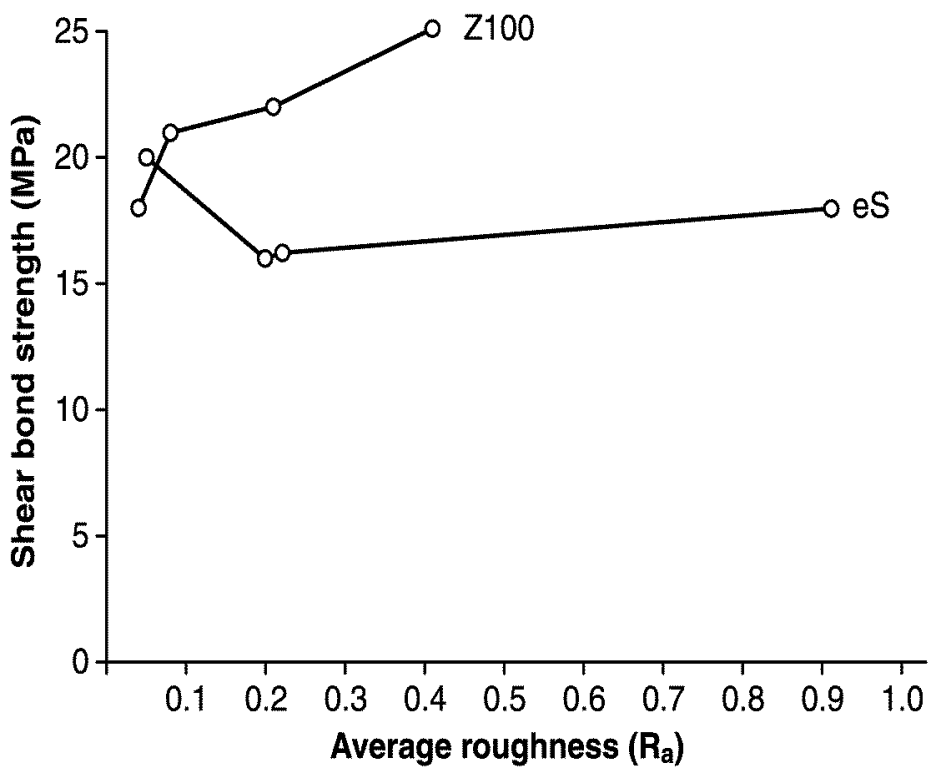

Fig. (2). Average surface roughness $\left(\mathrm{R}_{\mathrm{a}}\right)$ plotted against shear bond strength in $\mathrm{MPa}$.

The shear bond strength values for all groups were analysed with analysis of variance (ANOVA) using SPSS 10.0 (Statistical Package for Social Science, SPSS Inc., Chicago, Illinois, USA). Weibull analysis was carried out to calculate characteristic bind strength and Weibull modulus. The primary form of the Weibull distribution is described below:

$$
P_{f}=1-\exp \left(-\left(\left(\sigma-\sigma_{\mathrm{u}}\right) / \sigma_{0}\right)\right)^{m}
$$

where $\mathrm{m}=$ Weibull modulus (also known as a shape factor), a constant, which determines the slope of the distribution function and characterizes the spread of the failure data with respect to the $\sigma$ (=strength) axis. $\sigma_{0}=$ characteristic strength (i.e the stress level at which $63 \%$ of the specimens have failed) and $\sigma_{\mathrm{u}}=$ theoretical failure stress at which the failure probability approaches zero and is known as the threshold stress $(\mathrm{MPa}) . \mathrm{P}_{\mathrm{f}}$ is the probability of failure, which varies from 0 to 1 . The correlation coefficient $r$ was calculated from linear regression models with logarithmic transformations.

\section{RESULTS}

The average surface roughness $\left(R_{a}\right)$ of composite $Z 100$ decreased from 0.41 to 0.04 by changing the grit size of grinding papers from 320 to 2400 (Table 2). FRC eS showed higher roughness than composite Z100 after it was ground with 320 grit grinding paper $(\mathrm{Ra}=0.91)$ but the difference with Z100 decreased with the use of 800 to 2400 grit grinding papers. No difference was detected in the surface roughness when the FRC eS was measured transversally or longitudinally to the direction of the fibers. A rougher surface of composite Z100 resulted in higher shear bond strength values than a smoother surface $(p<0.001)$ (Fig. 1). Surface roughness of FRC eS with two fibre directions did not differ statistically $(p>0.05)$. The substrate ground with 2400 grit grinding paper obtained the highest bond strength, i.e. the smoothest surface (Fig. 1). Fig. (2) presents the average shear bond strength values plotted against surface roughness. Fracture patterns by visual analysis and light microscope showed mainly adhesive failures for the Z100 substrate and 
Table 3. Results of the Weilbull Analysis

\begin{tabular}{|c|c|c|c|}
\hline Group & Characteristic Strength = So & $\begin{array}{c}\text { Weibull } \\
\text { Modulus }=\mathbf{m}\end{array}$ & Correlation r-Coefficient \\
\hline \hline eS-320 grit & 20.885 & 1.940 & 0.984 \\
\hline eS-800 grit & 18.858 & 3.357 & 0.969 \\
\hline eS-1200 grit & 18.310 & 2.420 & 0.936 \\
\hline eS-2400 grit & 21.652 & 4.713 & 0.932 \\
\hline Z100-320 grit & 27.805 & 2.085 & 0.959 \\
\hline Z100-800 grit & 24.580 & 2.787 & 0.936 \\
\hline Z100-1200 grit & 18.310 & 2.420 & 0.973 \\
\hline Z100-2400 grit & 20.752 & 2.632 & 0 \\
\hline
\end{tabular}

cohesive failures for FRC with a debonding of individual fibers from the polymer matrix. No signs of intermediate resin existed on the surface.

A surface roughened by 320 grit grinding paper had the highest characteristic bond strength $(27.805 \mathrm{MPa})$ with composite Z100, but a roughness obtained with 800 grit grinding paper had the highest Weibull modulus (2.787) (Table 3) (Fig. 3a). With the FRC eS, the smoothest substrate surface, i.e. after it was ground with 2400 grit grinding paper, had the highest characteristic bond strength $(21.652 \mathrm{MPa})$ and Weibull modulus (4.713)(Table 3)(Fig. 3b).

\section{DISCUSSION}

Interlocking roughness could be described as an essential component of micromechanical retention in order to distinguish it from gross mechanical retention [26]. Gross retention refers to matter which prevents a restoration from falling out. It is used for amalgam and other direct restorative materials. Interlocking roughness is a smaller scale method of resisting shear or tensile forces. In this study, roughness represents micromechanical retention. Methodologically one needs to take into consideration that analysis of shear bond strength is typically combined with fracture pattern analysis of brittle materials. However, in this study, the substrate was a polymer based anisotropic FRC with a different fibre orientation for each study group. The substrate also contained an isotropic particulate filler composite. This makes statistical evaluation according to the classic Griffit's critical defect theory [27] of brittle isotropic materials difficult. Therefore the results of the Weibull analysis can only be considered indicative. Furthermore, the fracture pattern analysis is influenced by the diffusion of intermediate resin (Multipurpose adhesive) to the polymer matrix which is slightly plasticized in nature. This means that no remnants of the polymerized intermediate resin could be found visually. It is possible that differences in the elastic modulus of the substrate could have diffused and polymerized the intermediate resin as well as bonded the particulate filler composite resin, changing the gradient of the mechanical structure from a more resilient material towards a more brittle material. This could have influenced the fracture mechanics and stress distribution.
The present study did not support the expectation that rougher surfaces would improve the shear bond strength of one composite to another composite. It was interesting that, in the case of the FRC eS substrate, a rough surface did not provide better shear bond strength. It was assumed that the rough grinding paper would create more microscopic undercuts in the FRC eS substrate matrices then the composite Z100 substrate. Composite substrate is composed of polymer matrix and exposed inorganic fillers or fibers as bonding sites for new resins. Boyer and Chan [9] found that highly filled composites exhibited the highest bond strengths. In the case of focusing on improving the bonding of resins to the surface of inorganic fillers, silane coupling agents may provide improvement for bonding. Silane function is based on the existence of hydroxyl groups on the surface of an inorganic substrate. Due to this, the use of silane function is not applicable with polymer substrates [28].

Polymer matrices of commonly used filling composite resins and the majority of brands of FRCs are based on dimethacrylates which form a highly cross-linked polymer after they are polymerized. Cross-linked polymers are difficult to swell and dissolve in order to obtain an optimal penetration of monomers of the repair resin into the polymer structure of the substrate. This complicates the bonding of old composite resins to new resins. Alternatively, existence of non cross-linked polymer phases in the polymer matrix of composites, e.g. in the form of semi-interpenetrating polymer networks (IPN), allows bonding to occur by way of substrate dissolution and the penetration of new resin into the polymer structure [29]. This study used a cross-linked matrix in composite Z100 and an IPN matrix in FRC eS. The results demonstrated better bonding to the cross-linked matrix if the surface was rough, whereas IPN matrix demonstrated better bonding with a smooth surface. This indicates that the benefits of a polymer bonding surface with an IPN structure can be utilized even with smooth bonding surfaces. Lastumäki et al. [8] determined that the intermediate resin used in their study (MP) had relatively good dissolution capacity in the linear phases of the polymer matrix of the FRC eS substrate. Before polymerization of the new resin, the monomers of the intermediate resin had already swollen the IPN containing polymer matrix of the substrate and durable bonding was 


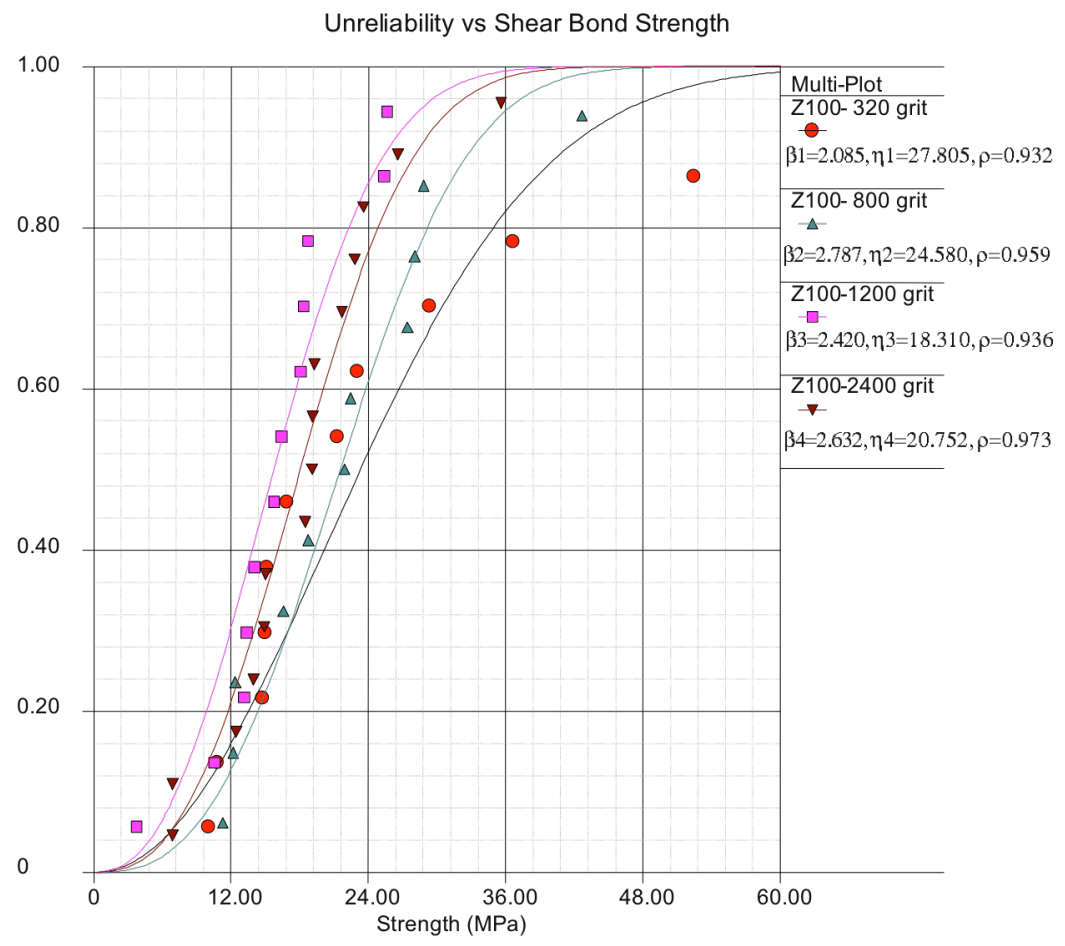

a)

Unreliability vs Shear Bond Strength

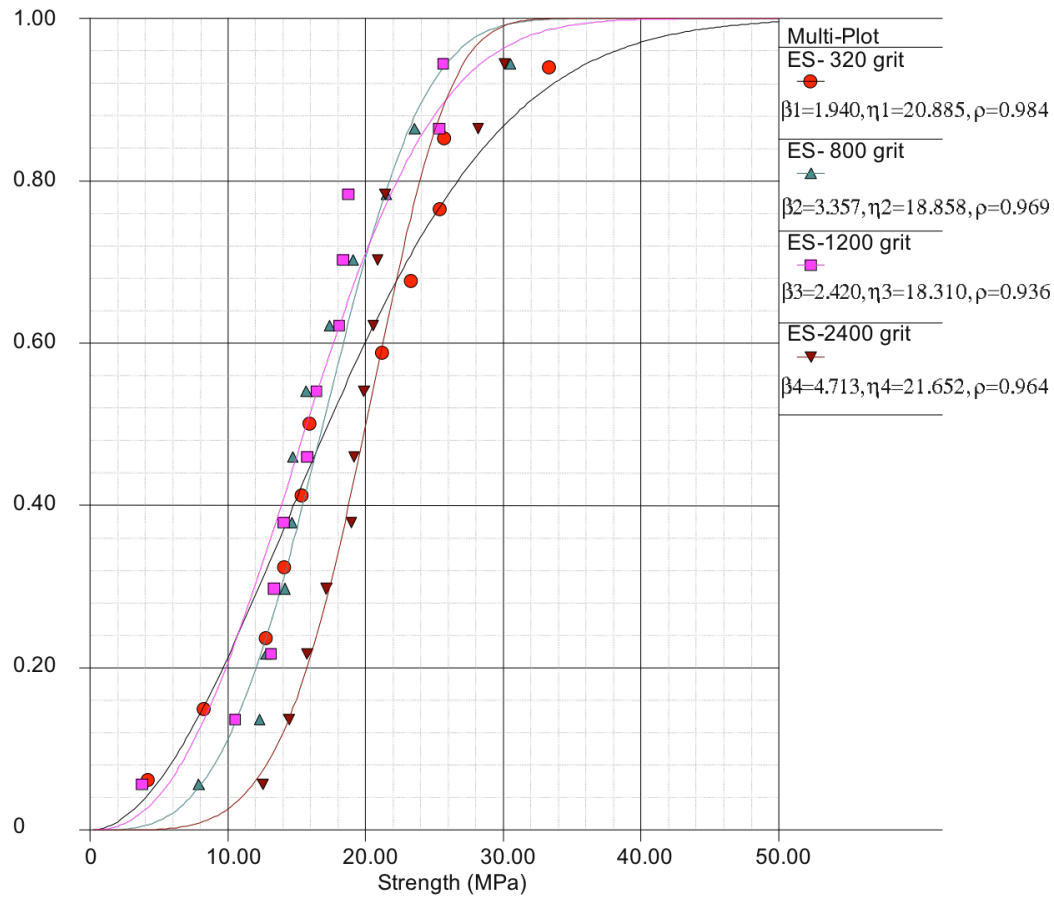

b)

Fig. (3). Graphs of the results of Weilbull analysis: a) composite Z100 and b) FRS eS.

established. Bond strength was not dependent on micromechanical irregularities as in the case of highly cross-linked composite substrate, due to the multiphase structure of the FRC substrate.

Earlier studies have shown that bond strength decreases when the oxygen inhibited surface layer of the substrate is removed or impaired [9, 30-32]. The possibility of obtaining free radical polymerization after the substrate surface is ground down is relatively low due to a small number of unreacted carbon-carbon double bonds on the polymer surface $[8,30]$. The highest reaction between a substrate and the formation of a covalent bond occurred during the first 24 hours after polymerization of the substrate [31, 33]. In this study, the substrates were aged for one week. This is likely 
the explanation why the bond strength of the composite substrate was dependent on micromechanical interlocking in the case of composite Z100, whereas bonding seemed to contribute to the bonding mechanism of swelling and dissolving the IPN matrix in the case of FRC eS. It is likely that fresh composite resin substrate would have provided better bond strength.

Our study concludes that surface roughness did not improve the bonding of new resin to the substrate of IPN based fiber-reinforced composite, whereas the roughness contributed to bonding the new resin to the particulate filler composite resin with a cross-linked polymer matrix.

\section{DECLARATION OF INTERESTS}

Pekka Vallittu consults Stick Tech LTD in research and development.

\section{CONFLICT OF INTEREST}

The authors confirm that this article content has no conflicts of interest.

\section{ACKNOWLEDGEMENTS}

Declared none

\section{REFERENCES}

[1] Rosentritt M, Behr M, Leibrock A, Handel G, Friedl K. Intraoral repair of fiber-reinforced composite fixed partial dentures. J Prosthet Dent 1998;79: 393-8.

[2] Kallio TT, Lastumäki TM, Vallittu PK. Bonding of restorative and veneering composite resin to some polymeric composites. Dent Mater 2001; 17: 80-6.

[3] Vallittu PK, Sevelius C. Resin-bonded, glass fiber-reinforced composite fixed partial dentures: a clinical study. J Prosthet Dent 2000; 84: 413-8.

[4] Vallittu PK. Prosthodontic treatment with a glass fiber-reinforced resin-bonded fixed partial denture: A clinical report. J Prosthet Dent 1999; 82: 132-5.

[5] Sewon LA, Ampula L, Vallittu PK. Rehabilitation of a periodontal patient with rapidly progressing marginal alveolar bone loss: 1-year follow-up. J Clin Periodontol 2000; 27: 615-9.

[6] Goldberg AJ, Burstone CJ. The use of continuous fiber reinforcement in dentistry. Dent Mater 1992; 8:197-202.

[7] Freilich MA, Duncan JP, Meiers JC, Goldberg AJ. Preimpregnated fiber-reinforced prostheses. Part I. Basic rationale and completecoverage and intracoronal fixed partial denture designs. Quintessence Int 1998; 29: 689-96.

[8] Tezvergil A, Lassila LVJ, Vallittu PK. Composite-composite repair bond strength: effect of different adhesion primers. J Dent 2003; 31:521-5.

[9] Lastumäki TM, Kallio TT, Vallittu PK. The bond strength of lightcuring composite resin to finally polymerized and aged glass fiberreinforced composite substrate. Biomaterials 2002; 23: 4533-9.

[10] Lloyd CH, Baigrie DA, Jeffrey IW. The tensile strength of composite repairs. J Dent 1980; 8:171-7.
[11] Boyer DB, Chan KC, Reinhardt JW. Build-up and repair of lightcured composites: bond strength. J Dent Res 1984; 63:1241-4.

[12] Söderholm K-JM, Roberts MJ. Variables influencing the repair strength of dental composites. Scand J Dent Res 1991; 99:173-80.

[13] Özcan M, Alander P, Vallittu PK, Huysmans MC, Kalk W. Effect of three surface conditioning methods to improve bond strength of particulate filler resin composites. J Mater Sci Mater Med 2005; 16: 21-7.

[14] Meiers JC, Duncan JP, Freilich MA, Goldberg AJ. Preimpregnated, fiber-reinforced prostheses. Part II. Direct applications: Splints and fixed partial dentures. Quintessence Int 1998; 29:761-8.

[15] Nilsson E, Alaeddin S, Karlsson S, Milleding P, Wennerberg A. Factors affecting the shear bond strength of bonded composite inlays. Int J Prosthodont 2000;13: 52-8.

[16] Tam LE, McComb D. Shear bond strengths of resin luting cements to laboratory-made composite resin veneers. J Prosthet Dent 1991; 66: 314-21.

[17] Eli I, Liberman R, Levi N, Haspel Y. Bond strength of joined posterior light cured composites: Comparison of surface treatments. J Prosthet Dent 1988; 60:185-8.

[18] Kallio TT, Lastumäki TM, Vallittu PK. Effect of resin application time on bond strength of polymer substrate repaired with particulate filler composite. J Mater Sci Mater Med 2003; 14:1-6.

[19] Azarbal P, Boyer DB, Chan KC. The effect of bonding agents on the interfacial bond strength of repaired composites. Dent Mater 1986; 2 : 153-5.

[20] Shahdad SA, Kennedy JG. Bond strength of repaired anterior composite resins: an in vitro study. J Dent 1998; 26: 685-94.

[21] Mitsaki-Matsou H, Karanika-Kouma A, Papadoyiannis Y, Theodoridou-Pahine S. An in vitro study of the tensile strength of composite resins repaired with the same or another composite resin. Quintessence Int 1991; 22: 475-81.

[22] Crumbler DC, Bayne SC, Sockwell S, Brunson D, Robertson TM. Bonding to resurfaced posterior composites. Dent Mater 1989; 5: 417-24.

[23] Swift EJ, LeValley BD, Boyer DB. Evaluation on new methods for composite repair. Dent Mater 1992; 8: 362-5.

[24] Kupiec KA, Barkmeier WV. Laboratory evaluation of surface treatments for composite repair. Oper Dent 1996; 21(2): 59-62.

[25] Turner CW, Meiers JC. Repair of an aged, contamined indirect composite resin with a direct, visible-light-cured composite resin. Oper Dent 1993; 18:187-94.

[26] Chan KC, Boyer DB. Repair of conventional and microfilled composite resins. J Prosthet Dent 1983; 50: 345-50.

[27] Darvell BW. Materials Science for Dentistry. $7^{\text {th }}$ ed. Hong Kong: Darvell Publishing 2002; p. 205

[28] Della Bona A, van Noort R. Shewar vs. tensile bond strength of resin composite bonded to ceramic. J Dent Res 1995; 74:1591-6.

[29] Matinlinna JP, Ozcan M, Lassila LVJ, Vallittu PK. The effect of 3methacryloxyproppyltrimethoxy-silane and vinyltriisopropoxysilane blend and tris(3trimethoxysilylpropyl)isocyanurate on the shear bond strength of composite resin to titanium metal. Dent Mater 2004; 20: 804-13.

[30] Mannocci F, Sheriff M, Watson TF, Vallittu PK. Penetration of bonding resins into fibre-reinforced composite posts: a Confocal microscopic study. Int J Endod 2005; 38: 46-51.

[31] Ruyter IE. Unpolymerized surface layers on sealants. Acta Odontol Scand 1981; 39: 27-32.

[32] Saunders WP. Effect of fatique upon the interfacial bond strength of repaired composite resins. J Dent 1990;18:158-62.

[33] Li J. Effects of surface properties on bond strength between layers of newly cured dental composites. J Oral Rehabil 1997; 24: 358-60.

Received: July 05, 2013

(C) Kallio et al.; Licensee Bentham Open.

This is an open access article licensed under the terms of the Creative Commons Attribution Non-Commercial License (http://creativecommons.org/licenses/by-nc/3.0/) which permits unrestricted, non-commercial use, distribution and reproduction in any medium, provided the work is properly cited. 